\title{
Constructional Paradigm in Constraint-based Morphosyntax: A Case of Japanese Verb Inflection*
}

\author{
RYO OTOGURO
}

Waseda University

\section{Introduction}

It is a well-known fact that tense, aspect and mood/modality (TAM) are encoded in morphosyntactically diverse ways across languages. Some languages realise them purely by verb inflectional morphology, while others express them periphrastically by a verb and auxiliary/copula complex. Since Japanese is one of the languages that exhibit a combination of those two strategies in rather complicated manners, it poses a serious challenge to any grammatical theory as to how lexical verbs, auxiliaries, copulas, particles and inflectional suffixes are located in morphosyntactic structures, and how they are related to TAM functions in relevant components of the grammar. In the frameworks that place syntactic derivation in the central component of the grammar such as Minimalist Program and its variant, particularly in the recent development of syntactic structure above the proposition level (Rizzi 1997, Cinque 1999), it is assumed that mood suffixes head Fin(ite) or Mood projection and modal expressions and sentence final particles head Mod(al) or Force projection above T(ense) and Asp(ect) (Hasegawa 2009, Endo 2007). Lexicalist frameworks, on the other hand, maintain the division between word-internal and word-external structures. TAM realisation below $\mathrm{V}^{0}$-level, therefore, are operated

*I would like to thank Jong-Bok Kim, Kiyong Lee and David Y. Oshima for their comments and suggestions. The remaining errors and inadequacies are, of course, all my own. This work is supported by Grant-in-Aid for Young Scientist (B), Japan Society for the Promotion of Science (Grant No. 18820019). 


\section{Ryo Otoguro}

independently from syntax and a string of formatives are constructed in the lexicon (Sells 1995). This paper aims to give an account of controversial behaviours of complex interaction of verb inflection, auxiliary/copula constructions in Japanese in a constraint-based lexicalist formalism, Lexical-Functional Grammar (LFG; Kaplan and Bresnan 1982, Bresnan 2001, Dalrymple 2001, Falk 2001). Building on the insight from a construction-based approach to morphosyntax, the present study proposes that multiple lexical items interact with each other to realise a set of TAM features, while maintaining their phrase-structural autonomy. Crucially, the proposal enables us to capture 'constructional' exponents realising a certain combination of morphosyntactic features in the inflectional paradigm as well as the internal structure of the construction, so that we can observe the emergent properties of the construction in the grammar.

\section{Morphosyntax of TAM encoding}

Japanese, like many other languages, utilises a diverse range of lexical items such as lexical verbs, auxiliaries, adnominals, adjectival modal expressions and copulas to realise tense, aspect, mood and modality features as well as polarity and politeness. The basic combinatorial characteristics of those items are divided into the following patterns: (i) synthetic inflection of a single lexical verb; (ii) an analytic expression of a combination of a lexical verb and an auxiliary; and (iii) an addition of an adnominal and a copula to (i) or (ii). When more than one lexical item are combined as in (ii) and (iii), the question arises as to what kinds of morphological restrictions are observed across the items and how the items are syntactically related to each other. The following part of this section presents a descriptive overview of the patterns as well as the morphological and syntactic characteristics of the forms.

\subsection{Realisation patterns}

The verbs primarily inflect for polarity and politeness. The negative form is derived by adding an adjectival ending nai to the stem, so the inflectional patterns of negative forms are identical to regular adjectives, although their syntactic behaviours are still distinctively verbs (cf. Kishimoto 2008, Spencer 2008). When the mood is unmarked, namely the form is in the indicative mood, a tense distinction between past and non-past is observed as in (1). But the verbs also shows a range of inflectional forms for other mood features such as conditional, hortative and conjunctive as illustrated in (2).

(1) a. Taroo wa maiasa ringo o taberu.

Taro TOPIC every morning apple ACC eat.NONPAST

'Taro eats an apple every morning.'

b. Taroo wa kesa ringo o tabeta.

Taro TOPIC this morning apple ACC eat.PAST

'Taro ate an apple this morning.' 
Constructional Paradigm in Constraint-based Morphosyntax

c. Taroo wa ringo o tabenai.

Taro TOPIC apple ACC eat.NEG.NONPAST

'Taro doesn't eat an apple.'

d. Taroo wa ringo o tabemasita.

Taro TOPIC apple ACC eat.POLITE.PAST

'Taro ate an apple.'

a. maiasa ringo o tabereba, ...

every morning apple ACC eat.COND, ...

'If you eat an apple every morning, ...'

b. Taroo wa ringo o tabenaide ie o deta.

Taro TOPIC apple ACC eat.NEG.CONJ home ACC leave.PAST

'Taro left home without eating an apple.'

c. maiasa ringo o tabemasyoo.

every morning apple ACC eat.POLITE.HORT

'Let's eat an apple every morning.'

In addition to synthetic single word inflection, the verbs can also be combined with an auxiliary such as iru/aru 'exist', oku 'put', miru 'see', simau 'end' and yaru 'give', all of which have lost their lexical meanings in this usage and simply encode a range of aspectual features. The lexical verb preceding an auxiliary must be in non-finite, non-polite, affirmative or negative form, and the finite auxiliary inflects for polarity, politeness, tense and mood in the same way as the finite lexical verbs. (3) exemplifies the sentences involving auxiliary verbs, iru and oku, preceded by non-finite affirmative and negative lexical verbs respectively.

a. Taroo wa ringo o tabete iru.

Taro TOPIC apple ACC eat.NONFIN AUX.NONPAST

'Taro is eating an apple.'

b. ringo wa tabenaide okimasyoo.

apple TOPIC eat.NEG.NONFIN AUX.POLITE.HORT

'Let's not eat that apple.'

Furthermore, the verb complex can be extended by a copula. The copula can attach either to a finite lexical verb or to a finite auxiliary verb with the intervention of an adnominal ${ }^{1}$ such as no, hazu, yoo and tumori, which signal various types of modality. This intervention of adnominals are mandatory, that is the copula cannot be immediately adjacent to a lexical verb or an auxiliary. ${ }^{2}$ (4) illustrates that the combination of adnominal and copula follows the finite lexical and auxiliary verbs,

${ }^{1}$ The category term, adnominal, is taken from Martin (1975).

${ }^{2}$ Some adjectival modal items such as rasii 'seem (hearsay)' directly attach to the preceding finite verb. 


\section{Ryo Otoguro}

in which the adnominals encode epistemic modality, and the copulas inflect for politeness and tense.

a. Taro wa ringo o taberu hazu datta.

Taro TOPIC apple ACC eat.NONPAST ADN COPULA.PAST

'Taro was supposed to eat an apple.'

b. Tarowa ringo o tabenaide yoo

Taro TOPIC apple ACC eat.NEG.NONFIN AUX.PAST ADN

desu.

COPULA.POLITE.NONPAST

'It seems that Taro didn't try to eat an apple.'

Finally, a sentence final particle can be added after the verb complex. In (5), the particles, ne and yo, are added to the finite lexical verb and the verb complex respectively and represent the speaker's psychological attitude towards the propositions.

a. Taroo wa ringo o tabemasita ne.

Taro TOPIC apple ACC eat.POLITE.PAST FPART

'Taro ate an apple, didn't he?'

b. Taroo wa ringo o tabenaide oita yoo

Taro TOPIC apple ACC eat.NEG.NONFIN AUX.PAST ADN

desu yo

COPULA.POLITE.NONPAST FPART

'It seems that Taro tried not to eat an apple.'

To summarise the distributional patterns of the verb complex, the following linear order is obtained:

(6) Linear order of Japanese verb complex

$$
\mathrm{V}_{\text {lex }}-\mathrm{V}_{\text {aux }}-\mathrm{ADN}-\mathrm{V}_{\text {copula }}-\mathrm{F} . \text { Part }
$$

With regard to the morphological constraints, the auxiliary requires the preceding lexical verb to be in the non-finite form; while the adnominal and copula complex requires the preceding verb, regardless of whether it is a lexical or auxiliary verb, to be in the tensed form. Thus, any grammatical theory needs to capture not only the linear distributions of items, but also the morphological dependency relations across the components within a verb complex. Since final particles always appear sentence-finally, regardless of the category of the preceding phrase, they are treated as a clause-level, i.e. root, adjunction, and outside the scope of the present study.

\subsection{Clausality}

When more than one lexical item construct a verb complex, a question arises as to whether they constitute a single clause or not. In the case of a combination 


\section{Constructional Paradigm in Constraint-based Morphosyntax}

of lexical and auxiliary verbs, the clausal morphosyntactic features such as tense, negation and politeness are marked only once. Therefore, as shown in (3) above, tense and politeness are marked only once on the auxiliary verbs. Further, if the non-finite lexical verb is in the negative form, the negative polarity is not allowed to be marked doubly on the auxiliary as shown in (7). Thus, we can plausibly conclude that they constitute a single clausal unit.

(7) *Taroo wa ringo o tabenaide okanai.

Taro TOPIC apple ACC eat.NEG.NONFIN AUX.NEG

The adnominal and copula complex, on the other hand, constitutes a separate clause from the preceding lexical verb or the lexical and auxiliary verb complex. This point can clearly observed in (4) above, where distinct tense markings are possible between the copula and the preceding part.

In addition to the feature distributional patterns, a further piece of evidence of mono-clausality of the lexical verb and auxiliary complex and bi-clausality between the copula and the preceding part comes from the behaviour of a verbal proform. (8) demonstrates that the A utterance can be a reply either to question $\mathrm{Q}_{1}$ or $\mathrm{Q}_{2}$. The adnominal and the copula complex take the verbal proform, sono, as its complement and that proform anaphorically refers to the phrase headed by a lexical verb like $\mathrm{Q}_{1}$ or a lexical verb and auxiliary complex like $\mathrm{Q}_{2}$. This anaphoric reference by a proform strongly suggests that the adnominal and the copula introduces a separate clause by taking the preceding part as a syntactic complement.

$$
\begin{aligned}
& \mathrm{Q}_{1} \text { : Taroo wa ringo o tabeta no? } \\
& \text { Taro TOPIC apple ACC eat.PAST FPART } \\
& \text { 'Did Taro eat an apple?' } \\
& \mathrm{Q}_{2} \text { : Taroo wa ring o tabete iru no? }
\end{aligned}
$$

Taro TOPIC apple ACC eat.NONFIN AUX.NONPAST FPART

'Is Taro eating an apple?'
A: Un, sono hazu/yoo da
yo.
yes PRO ADN
COPULA.NONPAST FPART

The following conversational pairs in (9), on the other hand, illustrate that an anaphoric reference to the lexical verb by a proform, sono, is not possible $\left(\left(9-\mathrm{A}_{1}\right)\right)$; instead an adverbial soo 'so' and the non-finite form of suru 'do' must be used in such interpretation $\left(\left(9-\mathrm{A}_{2}\right)\right)$.

$$
\begin{aligned}
\text { Q: } & \text { Taroo wa ringo o tabete ita no? } \\
& \text { Taro TOPIC apple ACC eat.NONFIN AUX.PAST FPART } \\
& \text { 'Was Taro eating an apple?' } \\
\mathrm{A}_{1}: & \text { *Un, sono ita yo. } \\
& \text { yes PRO AUX.PAST FPART }
\end{aligned}
$$




\section{Ryo Otoguro}

$$
\begin{aligned}
& \mathrm{A}_{2}: \begin{array}{l}
\text { Un, soo site } \\
\text { yes so do.NONFIN AUX.PAST FPART }
\end{array}
\end{aligned}
$$

This impossibility of an anaphoric reference by a verbal proform indicates that the lexical verb does not constitute a clausal complement of the following auxiliary.

\subsection{Constructional exponents}

The analytic inflectional patterns we have looked at so far are compositional, in that morphosyntactic features of the verb complex are obtained by unification of the features each lexical item in the complex carries. However, the number of features one lexical item realises is not unlimited. For instance, Japanese has an idiosyncratic gap of the negative, polite, past form in the inflectional paradigm. Thus, to realise all of those features, they must be distributed across exponents in the analytic form.
a. tabenaide imasita
eat.NEG.NONFIN AUX.POLITE.PAST
b. tabemasen desita
eat.NEG.POLITE COPULA.POLITE.PAST
c. tabete imasen desita
eat.NONFIN AUX.NEG.POLITE COPULA.POLITE.PAST

In (10a), the negative feature is encoded in the lexical verb and the remaining two features, polite and past, are realised by the auxiliary. However, if an auxiliary is absent in the verb complex, namely any aspectual feature that must be realised by an auxiliary is not involved, the verb complex is obligatorily extended in order to involve a copula, which encodes the remaining past tense feature as well as the doubly marked politeness feature, as in (10b) (cf. Otoguro 2007, Spencer 2008). Even with a presence of an auxiliary verb, the copula must be introduced if the lexical verb realises none of three features. This is due to the lack of a negative, polite, past form of an auxiliary. Hence, in (10c) the auxiliary realises the negative, polite features while the copula encodes the polite, past features.

The peculiarity of the analytic expression like $(10 \mathrm{~b}, \mathrm{c})$ is an absence of an adnominal item before the copula. In principle, the copula requires an adnominal item to intervene between the copula and the preceding finite verb as shown in (11) (see also (4)). In the case of periphrastic realisation patterns of negative, polite, past features, however, the adnominal must not appear between the lexical/auxiliary verb and the copula as shown in (12).
a. tabeta *(no) desu
eat.PAST COPULA.POLITE.NONPAST
b. tabenaide oita *(no) da
eat.NEG.NONFIN AUX.PAST COPULA.NONPAST 


\title{
Constructional Paradigm in Constraint-based Morphosyntax
}

\author{
a. tabemasen (*no) desita \\ eat.NEG.POLITE COPULA.POLITE.PAST \\ b. tabete imasen (*no) desita \\ eat.NONFIN AUX.NEG.POLITE COPULA.POLITE.PAST
}

Further, the politeness value of a copula used in this pattern must be consistent with that of the preceding verb as illustrated by the ungrammaticality of (13a, b). Such consistency is not mandatory in regular patterns involving adnominals as show in $(13 c, d)$.
a. *tabemasen datta eat.NEG.POLITE COPULA.PAST
b. *tabete imasen datta
eat.NONFIN AUX.NEG.POLITE COPULA.PAST
c. taberu no desita
eat.NONPAST ADN COPULA.POLITE.PAST
d. tabete iru no desita
east.NONFIN AUX.NONPAST ADN COPULA.POLITE.PAST

The behaviours the periphrastic negative, polite, past expression exhibits clearly indicates that the copula and the preceding verb(s) constitute a single clausal unit. Moreover, the deviation from regular compositional patterns can be attributed to 'constructional' nature of this periphrastic exponents (Sadler and Spencer 2001, Ackerman and Stump 2004, Booij 2010, Ackerman et al. 2011). Thus, the grammar must be able to utilise this type of construction only when a certain set of morphosyntactic features are realised.

\section{Analysis}

Building upon the descriptive observation made in the previous section, I will present an analysis of the synthetic and analytic verb inflectional patterns in Japanese within a constraint-based grammar, LFG. The analysis is based on the recent development of the framework called projection architecture (Kaplan 1995, Butt et al. 1996), in which different types of linguistic information are represented in separate components of the grammar in a parallel fashion and the correspondence between the components is established by mapping functions. In the present study, the relevant components are $\mathrm{c}$ (onstituent)-structure, $\mathrm{f}$ (unctional)-structure and $\mathrm{m}$ (orphological)-structure. The essence of the analysis is to encode phrasestructural, morphological and syntactic complementations in separate components of the grammar, so that the diverse range of inflectional patterns found in the language is captured. 


\section{Ryo Otoguro}

\subsection{Projection architecture}

The c-structure configuration of the entire verb complex is represented as in (14). As standardly assumed in LFG, each node is given annotations that define projections from the c-structure node to other structures. $\uparrow$ and $\downarrow$ are abbreviations of $\phi(M(*))$ and $\phi(*)$ respectively, in which $\phi$ is a function that maps a c-structure node to an f-structure, $M$ maps a c-structure node to its mother node, and $*$ refers to the current c-structure node, i.e. the node to which the annotation is given. In a similar fashion, $\widehat{*}_{\mu}$ and $*_{\mu}$ are abbreviated functions of $\mu(M(*))$ and $\mu(*)$ respectively, in which $\mu$ is a mapping function from a c-structure node to an m-structure. Therefore, $\uparrow=\downarrow$ means that the syntactic features associated with the current node is mapped onto the same f-structure as those associated with the mother node. And similarly, $\widehat{*}_{\mu}=*_{\mu}$ states that the morphological features associated with the current node is mapped onto the same m-structure as those associated with the mother node. Since the lexical and auxiliary verb complex is a syntactic complement of the following adnominal and copula complex, the $\mathrm{V}$ node dominating those two verbs is given an annotation $\left(\uparrow \mathrm{XCOMP}^{*}\right)=\downarrow$, which ensures that the syntactic features of the two verbs are mapped onto the value of XCOMP, an open complement, of the larger clause headed by the copula. ${ }^{3}$ That is, the f-structure corresponding to this c-structure is bi-clausal. In terms of morphological dependency, the auxiliary selects a non-finite lexical verb, so $\left(\widehat{*}_{\mu} \mathrm{DEP}^{*}\right)=*_{\mu}$ ensures that the morphological features associated with the lexical verb are mapped onto the value of DEP, a morphological dependent, of the auxiliary verb in the m-structure. The same relationship is established between the adnominal and copula complex and its sister $\mathrm{V}$, so $\left(\widehat{*}_{\mu} \mathrm{DEP} *\right)=*_{\mu}$ is assigned to that node as well.

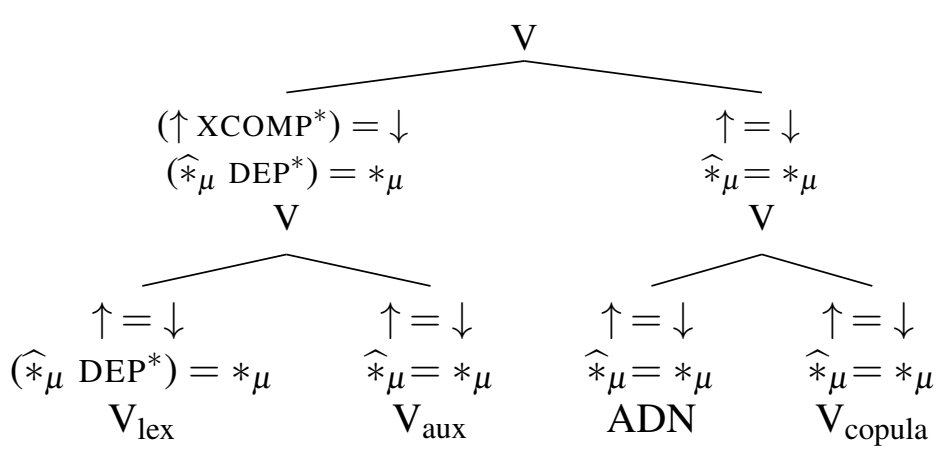

The morphological and syntactic features are lexically specified in the entries of the items of a verb complex, so that they are unified and mapped onto an fstructure and an m-structure according to the annotations given in the c-structure. For instance, the lexical entries (16) are given to the items of the verb complex, tabete ita yoo desu in (15):

\footnotetext{
${ }^{3}$ The kleene star $\left(^{*}\right)$ attached to XCOMP means that any number of XCOMP including zero can apply in this equation, as long as the relevant constraints are satisfied. The same mechanism applies to the kleene star attached to DEP.
} 
(15) Taroo wa ringo o tabete ita yoo

Taro TOPIC apple ACC eat.NONFIN AUX.PAST ADN

desu.

COPULA.POLITE.NONPAST

'It seems that Taro was eating an apple.'

a. tabete $\mathrm{V}_{\text {lex }}\left(\widehat{*}_{\mu}\right.$ FORM $)=$ lex

$\left(\widehat{*}_{\mu}\right.$ FIN $)=-$

$\left(\widehat{*}_{\mu} \mathrm{NEG}\right)=-$

$(\widehat{*} \mu$ POLITE $)=-$

$(\uparrow \mathrm{PRED})=$ 'eat $\langle$ SUBJ,OBJ $\rangle$ '

b. ita $\mathrm{V}_{\mathrm{aux}} \quad\left(\widehat{*}_{\mu}\right.$ FORM $)=a u x$

$\left(\widehat{*}_{\mu}\right.$ FIN $)=+$

$\left(\widehat{*}_{\mu}\right.$ TENSE $)=+$

$(\widehat{*} \mu \mathrm{NEG})=-$

$(\widehat{*} \mu$ POLITE $)=-$

$\left(\widehat{*}_{\mu}\right.$ DEP FIN $)={ }_{c}-$

$\left(\widehat{*}_{\mu}\right.$ DEP POLITE $)={ }_{c}-$

$(\uparrow$ TENSE $)=$ PAST

$(\uparrow \mathrm{ASP})=\mathrm{PROG}$

c. yoo $\operatorname{ADN}\left(\widehat{*}_{\mu}\right.$ LINK $)=+$

$(\uparrow$ MODAL $)=$ EPISTEMIC

d. desu $\mathrm{V}_{\text {copula }}\left(\widehat{*}_{\mu}\right.$ FORM $)=$ copula

$\left(\widehat{*}_{\mu}\right.$ FIN $)=+$

$\left(\widehat{*}_{\mu}\right.$ TENSE $)=+$

$\left(\widehat{*}_{\mu} \mathrm{NEG}\right)=-$

$\left(\widehat{*}_{\mu}\right.$ POLITE $)=+$

$\left(\widehat{*}_{\mu}\right.$ LINK $)={ }_{c}+$

$\left(\widehat{*}_{\mu}\right.$ DEP FIN $)={ }_{c}+$

$\left(\widehat{*}_{\mu}\right.$ DEP TENSE $)={ }_{c}+$

$(\uparrow$ TENSE $)=$ NONPAST

$(\uparrow \operatorname{PRED})=$ 'copula $\langle$ XCOMP $\rangle$ SUBJ'

$(\uparrow \mathrm{XCOMP}$ SUBJ $)=(\uparrow \mathrm{SUBJ})$

The features mapped onto m-structure include FORM, FIN(iteness), TENSE, NEG(ative) and POLITE. The FORM specifies the type of an exponent as a lex(ical), aux(ilary) or copula verb. All the other features take boolean values, either + or - . The LINK is an inherent feature of adnominals, which licenses the preceding finite verb to be a complement of the following copula. The constraining equation, ${ }_{c}$, requires a certain value to be externally specified for a given feature. For example, $\left(\widehat{*}_{\mu}\right.$ DEP FIN $)={ }_{c}-$ and $\left(\widehat{*}_{\mu}\right.$ DEP POLITE $)={ }_{c}-$ specified in the entry of the auxiliary, ita, in (16b) require its morphological dependent to provide a negative value both for the attributes FIN and POLITE, which essentially ensures that the preced- 


\section{Ryo Otoguro}

ing lexical verb is in the non-finite, non-polite form. In a similar way, the copula requires a positive value to be externally specified for the attribute LINK as stated in (16d), so that it cannot occur without an adnominal like (16c). In (16d), two additional constraining equations are defined, both of which enable the copula to select a finite, tensed verb as its morphological dependent.

With regard to syntactic features, the lexical verb and the auxiliary are mapped onto the same f-structure and the former provides the PRED while the latter TENSE and ASP(ect). Since the copula takes a syntactic complement and introduces a biclausal structure as argued in section 1.2, it is treated as a raising verb as in the last two equations in the entry (16d). That is, the value of PRED states that it requires a thematic subject, SUBJ outside the angled brackets, and an open complement, XCOMP, and the athematic SUBJ is identified with the SUBJ inside the XCOMP. Finally, the adnominal contributes a MODAL feature to the outermost f-structure.

Based on the c-structure configurations in (14) and the lexical entries (16), the m-structure, marked with $\mu$, and the f-structure, marked with $\phi$, for the verb complex in (15) are given as follows: ${ }^{4}$

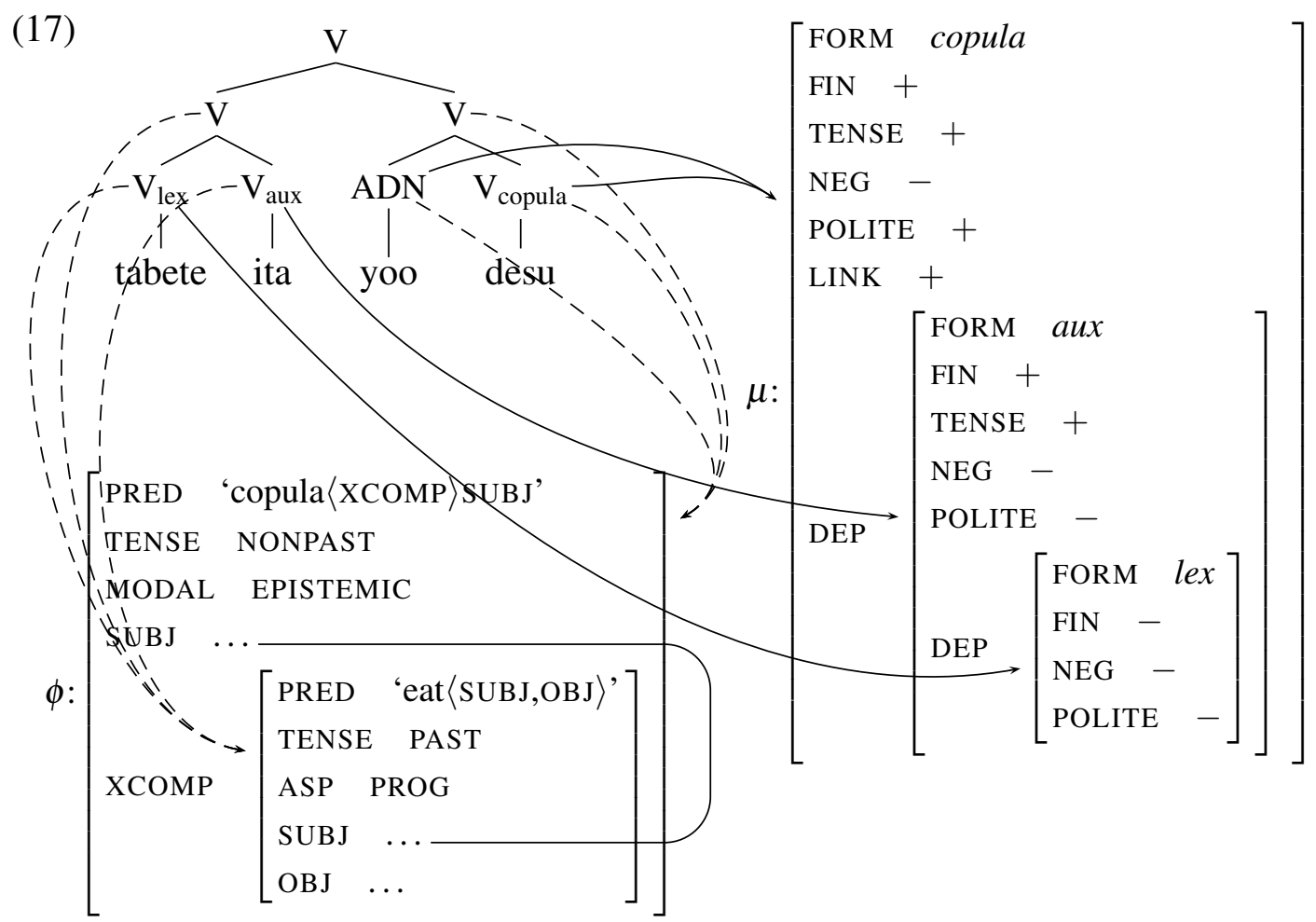

In the m-structure, the non-finite lexical verb is mapped onto the most deeply embedded DEP, which functions as the morphological dependent of the auxiliary. The

${ }^{4}$ The arrows represent the mapping from c-structure nodes to m-/f-structures. For ease of exposition, the structures only for the verb complex are given and the annotations on c-structure nodes are omitted. 


\section{Constructional Paradigm in Constraint-based Morphosyntax}

outer DEP corresponds to the finite auxiliary and functions as a morphological dependent of the the adnominal and the copula. The f-structure, on the other hand, is bi-clausal. Both the lexical verb and the auxiliary are mapped onto the value of XCOMP, namely they are syntactically a complement of the copula, so that the TENSE and ASP features of this clause come from the auxiliary while the PRED feature comes from the lexical verb. The TENSE and MODAL features associated with the adnominal and the copula are mapped onto the outer f-structure. Since the copula is treated as a raising verb, the athematic SUBJ in the outer f-structure is identified with the SUBJ in the XCOMP.

\subsection{Periphrastic inflection}

As argued in section 1.3, not all the analytic verb complex expressions are syntactically bi-clausal. When negative, polite, past features are distributed across the finite lexical/auxiliary verb and the copula, they constitute a single clausal unit. To account for this constructional exponents, the following lexical entries are postulated:

$$
\begin{aligned}
& \text { a. desita } \mathrm{V}_{\text {copula }}\left(\widehat{*}_{\mu} \text { FIN }\right)=+ \\
& \left(\widehat{*}_{\mu} \text { TENSE }\right)=+ \\
& \left(\widehat{*}_{\mu} \mathrm{NEG}\right)=- \\
& \left(\widehat{*}_{\mu} \text { POLITE }\right)=+ \\
& \left(\widehat{*}_{\mu} \text { LINK }\right) \neq+ \\
& \left(\widehat{*}_{\mu} \text { DEP NEG }\right)={ }_{c}+ \\
& \left(\widehat{*}_{\mu} \text { DEP POLITE }\right)={ }_{c}+ \\
& (\uparrow \text { TENSE })=\text { PAST } \\
& (\uparrow \text { STYLE })=\text { POLITE } \\
& \left(\widehat{*}_{\mu} \mathrm{NEG}\right)=+ \\
& \left(\widehat{*}_{\mu} \text { POLITE }\right)=+ \\
& (\uparrow \mathrm{POL})=\mathrm{NEG} \\
& (\uparrow \text { STYLE })=\text { POLITE } \\
& (\uparrow \mathrm{PRED})={ }^{\prime} \text { eat }\langle\text { SUBJ,OBJ }\rangle \text { ' }
\end{aligned}
$$

Since the copula used in this construction is restricted to the polite, past form, desita, this form is given an entry as in (18a) in addition to the regular raising verb usage. Crucial in the entry are the negative equation for LINK feature and the two constraining equations for NEG and POLITE features of its DEP. The equation, $\left(\widehat{*}_{\mu}\right.$ LINK $) \neq+$, stops an adnominal that introduces a positive value for LINK attribute from intervening between the copula and the preceding finite verb. The constraining equations, on the other hand, ensures that this special type of copula can appear only with a negative, polite form. With regard to syntactic features, it only contributes PAST value for TENSE and POLITE value for STYLE to the f-structure. Note that the entry lacks a PRED feature and relevant equations normally assigned to a raising verb (cf. (16d)). 


\section{Ryo Otoguro}

Those lexical items appear together in examples like (19), and the c-structure, $\mathrm{m}$-structure and f-structure corresponding to the verb complex in the example are given as in (20):

Taroo wa ringo o tabemasen desita.

Taro TOPIC apple ACC eat.NEG.POLITE COPULA.POLITE.PAST

'Taro didn't eat an apple.'

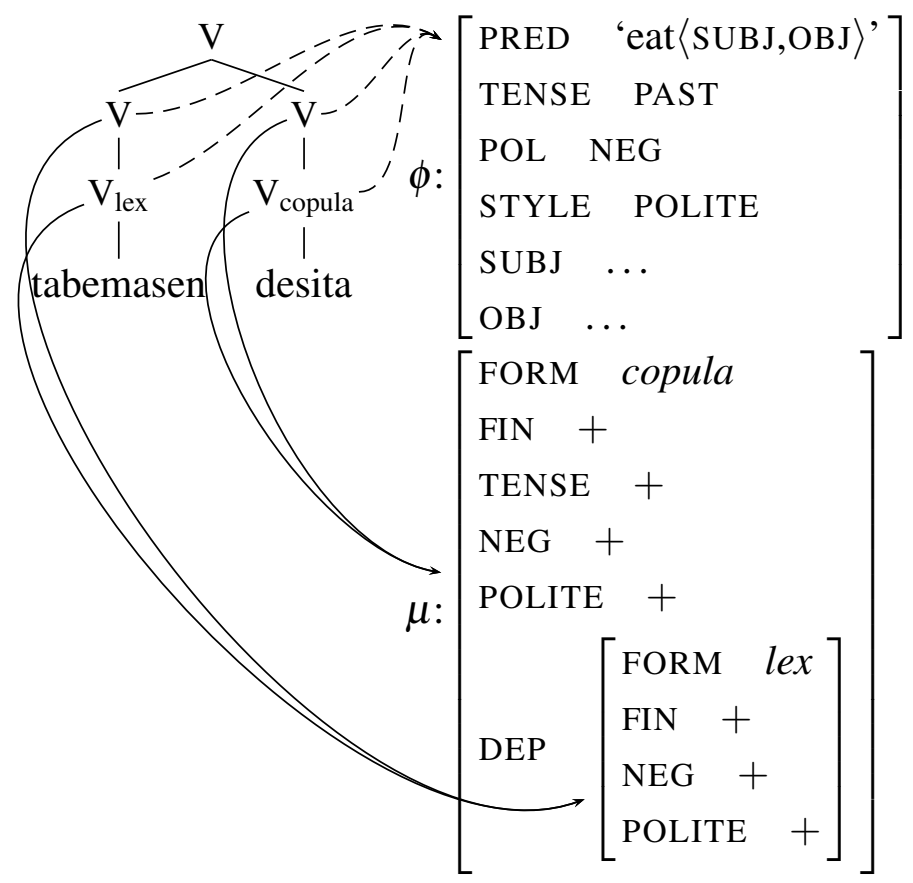

Since the annotation, $\left(\uparrow \mathrm{XCOMP}^{*}\right)=\downarrow$ on the c-structure node in (14) allows the $\mathrm{V}$ node headed by the lexical verb to be mapped onto the same f-structure as the copula, i.e. $\uparrow=\downarrow$, the f-structure for the verb complex constitutes a well-formed mono-clausal unit. The m-structure for the verb complex, on the other hand, includes a DEP embedding, namely the lexical verb is a morphological dependent of the copula. Therefore, the projection architecture allows us to account for the fact that the lexical verb is morphologically and phrase-structurally a complement of the copula while syntactically they constructs a single unit.

\section{Conclusion}

This paper demonstrates that careful inspection of the verb inflectional patterns in Japanese reveals that the language utilises a range of lexical items to realise TAM features in the verb domain, and the morphosyntactic relations across the items are not monolithic; instead they exhibit different types of complementations in terms of phrase structure, morphological dependency and syntactic clausal relations. This descriptive observation can formally be captured by a parallel constraint-based framework of LFG, in which distinct levels of representations are adopted as projection architecture. 


\section{Constructional Paradigm in Constraint-based Morphosyntax}

Crucially, the present study demonstrates that the feature realisation is not entirely compositional in Japanese, namely the distribution of the marked negative, polite, past features are constrained by construction as a whole. Such noncompositional nature of the exponents is widely observed across languages and often analysed by an explicit manifestation of construction types as found in recent work in Head-driven Phrase Structure Grammar (Sag 1997, Ginzburg and Sag 2000), Sign-based Construction Grammar (Boas and Sag to appear) and many others. Although this paper also attempts to account for the constructional exponents, the formalisation does not rely on an explicit reference to the construction itself; rather the concept of construction is formulated in such a way that it has emerged from regular compositional patterns of multiple lexical items. This type of formulation allows us to capture how construction is utilised in the grammar by maintaining the continuity with other part of the language.

\section{References}

Ackerman, Farrel, Gregory T. Stump, and Gert Webelhuth. 2011. Lexicalism, Periphrasis, and Implicative Morphology. In Robert D. Borsley and Kersti Börjars, eds., Non-Transformational Syntax: Formal and Explicit Models of Grammar, 323-358, Oxford: Blackwell.

Ackerman, Farrell and Gregory T. Stump. 2004. Paradigms and periphrastic expression: A study in realizaion-based lexicalism. In Louisa Sadler and Andrew Spencer, eds., Projecting Morphology, 111-157, Stanford, CA: CSLI Publications.

Boas, Hans C. and Ivan A. Sag, eds. To appear. Sign-Based Construction Grammar. Stanford, CA: CSLI Publications.

Booij, Geert. 2010. Construction Morphology. Oxford: Oxford University Press.

Bresnan, Joan. 2001. Lexical-Functional Syntax. Oxford: Blackwell.

Butt, Miriam, María-Eugenia Niño, and Frédérique Segond. 1996. Multilingual processing of auxiliaries within LFG. In Dafydd Gibbon, ed., Natural Language Processing and Speech Technology, Berlin: Mouton de Gruyter. Reprinted in Louisa Sadler and Andrew Spencer, eds., Projecting Morphology, 11-22, Stanford, CA: CSLI Publications.

Cinque, Guglielmo. 1999. Adverbs and Functional Heads: A Cross-linguistic Perspective. Oxford: Oxford University Press.

Dalrymple, Mary. 2001. Lexical Functional Grammar, Syntax and Semantics, vol- 


\section{Ryo Otoguro}

ume 34. San Diego: Academic Press.

Endo, Yoshio. 2007. Locality and Information Structure: A Cartographic Approach to Japanese. Amsterdam: John Benjamins.

Falk, Yehuda. 2001. Lexical-Functional Grammar: An Introduction to Parallel Constraint-Based Syntax. Stanford, CA: CSLI Publications.

Ginzburg, Jonathan and Ivan A. Sag. 2000. Interrogative Investigations: The Form, Meaning, and Use of English Interrogatives. Stanford, CA: CSLI Publications.

Hasegawa, Nobuko. 2009. Agreement at the CP level: Clause Types and the 'Person' Restrictions on the Subject. In The Proceedings of the Workshop on Altaic Formal Linguistics 5, 133-152, Cambridge, MA: MITWPL.

Kaplan, Ronald M. 1995. The formal architecture of Lexical-Functional Grammar. In Mary Dalrymple, Ronald M. Kaplan, John T. Maxwell, III, and Annie Zaenen, eds., Formal Issues in Lexical-Functional Grammar, 7-27, Stanford, CA: CSLI Publications.

Kaplan, Ronald M. and Joan Bresnan. 1982. Lexical-Functional Grammar: A Formal System for Grammatical Representation. In Joan Bresnan, ed., The Mental Representation of Grammatical Relations, 173-281, Cambridge, MA: MIT Press.

Kishimoto, Hideki. 2008. Negative Scope in Japanese. Journal of Linguistics 44:379-435.

Martin, Samuel E. 1975. A Reference Grammar of Japanese. New Haven: Yale University Press.

Otoguro, Ryo. 2007. Paradigm Gaps and Periphrases in the Japanese Conjugation System. In Proceedings of Western Conference on Linguistics 2007, 160-172, University of California, San Diego.

Rizzi, Luigi. 1997. The Fine Structure of the Left Periphery. In Liliane Haegeman, ed., Elements of Grammar, 281-338, Dordrecht: Kluwer.

Sadler, Louisa and Andrew Spencer. 2001. Syntax as an exponent of morphological features. In Geert Booij and Jaap van Marle, eds., Yearbook of Morphology 2000, 71-96, Dordrecht: Kluwer Academic Publishers.

Sag, Ivan A. 1997. English Relative clause Constructions. Journal of Linguistics 33:431-484.

Sells, Peter. 1995. Korean and Japanese morphology from a lexical perspective. 


\section{Constructional Paradigm in Constraint-based Morphosyntax}

Linguistic Inquiry 26:277-325.

Spencer, Andrew. 2008. Negation in Japanese: A Case of Morphosyntactic Mismatch. Lingua 118:997-1017.

Ryo Otoguro

Faculty of Law

Waseda University

1-6-1, Nishiwaseda, Shinjuku-ku, Tokyo, 169-8050, Japan

otoguro@waseda.jp 